\title{
Calculation of Pourbaix Diagrams for C22 in Various Well Water Chemistries
}

\section{Kaufman}

This article was submitted to

$5^{\text {th }}$ Nickel Development Institute Workshop on Fabrication and Welding of Nickel Alloys

Las Vegas, NV

October 16-17, 2002

\section{October 2, 2002}

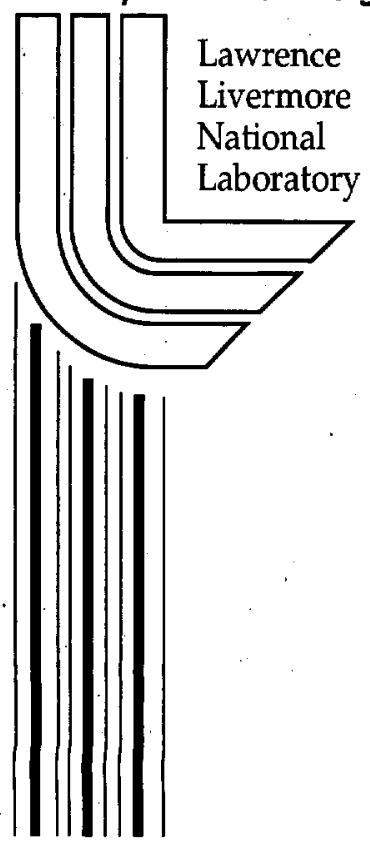




\section{DISCLAIMER}

This document was prepared as an account of work sponsored by an agency of the United States Government. Neither the United States Government nor the University of California nor any of their employees, makes any warranty, express or implied, or assumes any legal liability or responsibility for the accuracy, completeness, or usefulness of any information, apparatus, product, or process disclosed, or represents that its use would not infringe privately owned rights. Reference herein to any specific commercial product, process, or service by trade name, trademark, manufacturer, or otherwise, does not necessarily constitute or imply its endorsement, recommendation, or favoring by the United States Government or the University of California. The views and opinions of authors expressed herein do not necessarily state or reflect those of the United States. Government or the University of California, and shall not be used for advertising or product endorsement purposes.

This is a preprint of a paper intended for publication in a journal or proceedings. Since changes may be made before publication, this preprint is made available with the understanding that it will not be cited or reproduced without the permission of the author.

This report has been reproduced directly from the best available copy.

Available electronically at http://www.doc.gov/bridge

Available for a processing fee to U.S. Department of Energy

And its contractors in paper from

U.S. Department of Energy

Office of Scientific and Technical Information

P.O. Box 62

Oak Ridge, TN 37831-0062

Telephone: (865) 576-8401

Facsimile: (865) 576-5728

E-mail: reports@adonis.osti.gov

Available for sale to the public from

U.S. Department of Commerce

National Technical Information Service

5285 Port Royal Road

Springfield, VA 22161

Telephone: (800) 553-6847

Facsimile: (703) 605-6900

E-mail: orders@ntis.fedworld.gov

Online ordering: http://www.ntis.gov/ordering.htm

OR

Lawrence Livermore National Laboratory

Technical Information Department's Digital Library

http://www.llnl.gov/tid/Library.html 


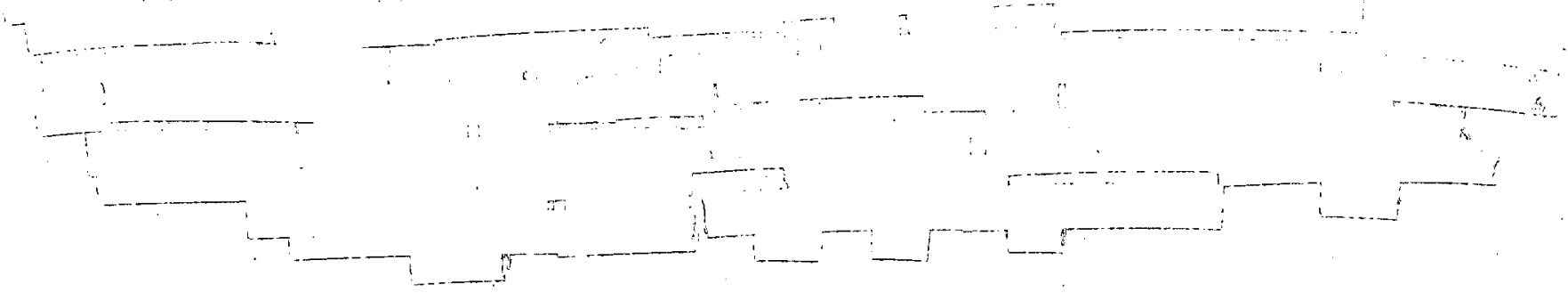

\title{
CALCULATION OF POURBAIX DIAGRAMS FOR C22 IN VARIOUS WELL WATER CHEMISTRIES*
}

\author{
Larry Kaufman,larrykaufman@rcn.com,Department of Materials Science and Engineering,MIT \\ 140 Clark Road,Brookline MA.02445-5848
}

\begin{abstract}
Aims and Scope.Design and Fabrication of the Waste Package for the Yucca Mountain Waste Package represents a formidable challenge of the total knowledge that exists today concerning the properties of a wide variety of materials systems.During the paste few years considerablr successs have been achieved by employing the techniques of the new "Computational Thermodynamics"CT[1] to address some of the most critical problems of phase stability with substantial success.In particular phase stability in Alloy C22 which is a complex 10 component alloy in order to define the temperature dependence of the solidification,welding, heat treatment and transformation kinetics of the condensed liquid,fcc.Sigma,P-Phase and $\mathrm{Ni}_{2} \mathrm{Cr}$ phases are very well described when the modern CT software and databases are applied.The present report provides a a description of current progress in the application of this technique to define and detail the corrosion behavior of $\mathrm{C}-22$ by using the Thermo-Calc software and data bases to apply the classic methods devised in the last cenury by Marcell Pourbaix[2] to C-22 in Simulated J-13 well waters(SAW)simulated acidic waters,SCW,simulated concentrated water and (BSW).The advantages of such a develop ment is that it could provide substantial insight into methods for predicting corrosion behavior in critical components of the Waste Package that will have to function predictably for many tens of thousands of years.
\end{abstract}

\section{Introduction}

Figures 1-7 are taken from the original work of Pourbaix[2] and serve as a primer on Pourbaix diagrams which provide a thermochemical background for aqueous corrosion.Figure 1 shows an overall view of the general behavior of metals in which the progression from noble metals at the top to reactive metals at the bottom is displayed!The field of these thumbnail descriptions is segmented into subunits that Pourbaix used to divide the space into regions of varying corrosion resistance. The abscissa is the $\mathrm{pH}$,defining the degree of acidity or bascicity of the solution and the Chemical potential of $\mathrm{H}+$ ions in the solution.Of course these fuctions are related thermodynamically as shown in Figures 2 and 3 which defines the range of stability of of liquid water on this phase diagram. Once these basic signposts are defined it is easy to review the thumbnail diagrams in Figure 1 and to begin to understand what they really mean.A greater appreciation of the details of the behavior of iron and nickel alloys as a precursor to C-22 can be gained by studying Figures 4-6.This includes the text accompanying Figures 4 and 5.The latter figures show the importance of the iron oxides which define the important regions of corrosion behavior in terms of the stability on the oxides and hydroxides of iron.The important details concerning oxide adherence and kinetics are noted on page 6.Finally Figure 7 shows a super postion of the Pourbaix diagrams for $\mathrm{Fe}$ and $\mathrm{Ni}$.

This report describes work that is in the early stages of progress that has been conducted under the Yucca Mountain Site Characterization Project at Lawrence Livermore Laboratory under Subcontract B-517930 from June 2001 through December 2001 and has been renewed to continue under Subcontarct B-5257737 for the period June 2002 through December 2002. This report was prepared 15 August 2002. 

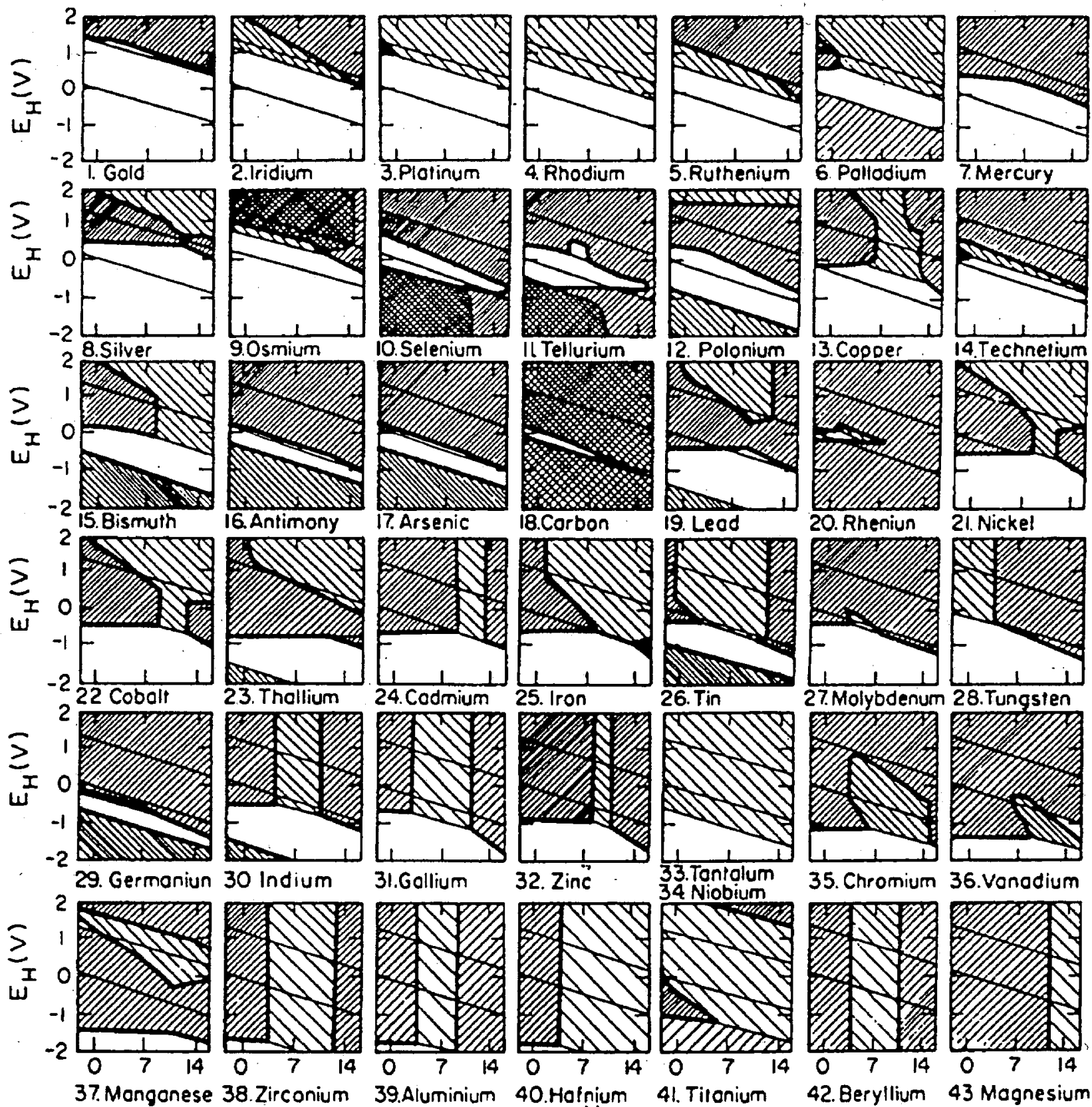

31.Gollium

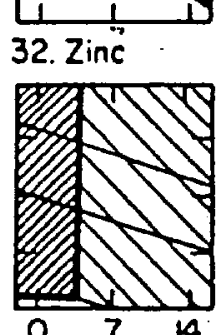

26. Tin
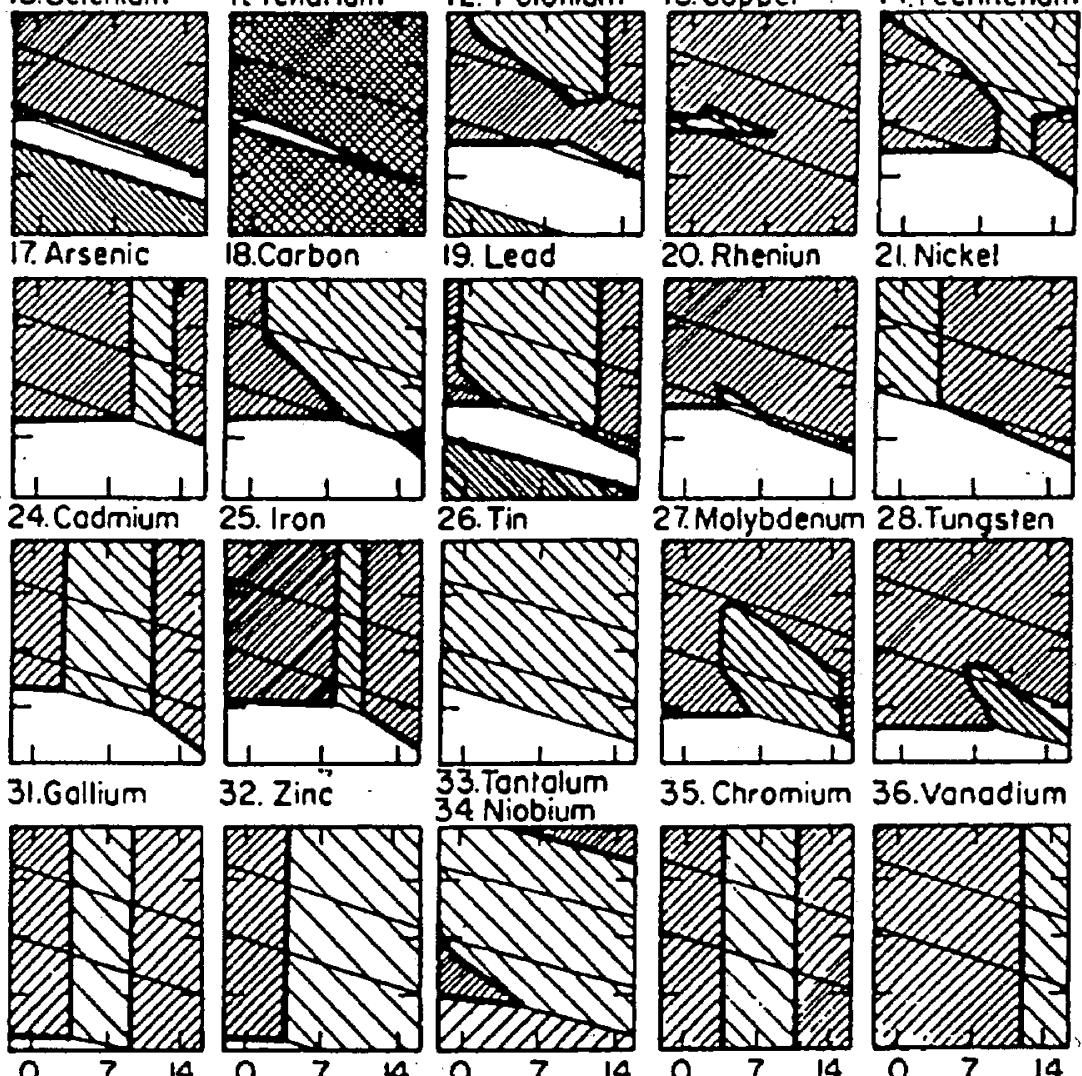

21. Nickel

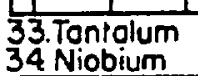

35. Chromium 36.vonodium
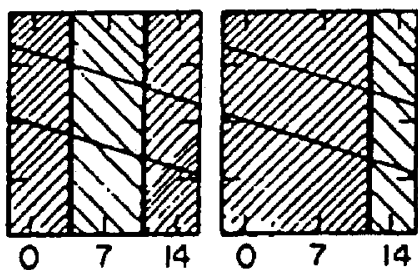

37. Monganese 38. Zirconium
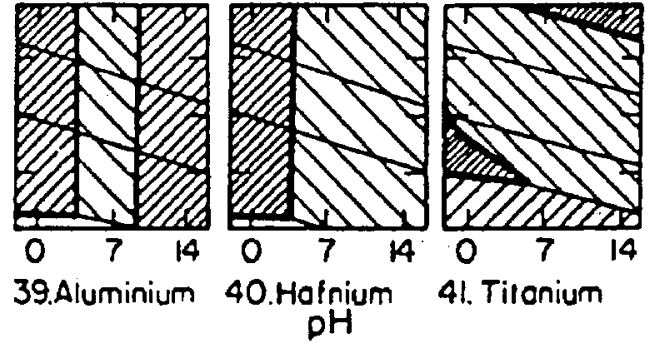

41. Tironium

42. Beryllium

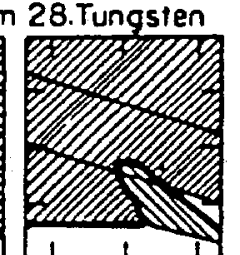

Corrosion Yielding Soluble Products
Passivation by o Film of Oxide or Hydroxide
$\begin{aligned} & \text { Possivation by a Film of Hydride } \\ & \text { Immunity }\end{aligned}$

Figure 1.Corrosion,immunity and passivation domains of metals and metalloids claffified in order of nobility due to thermodynamic immunity[1] 


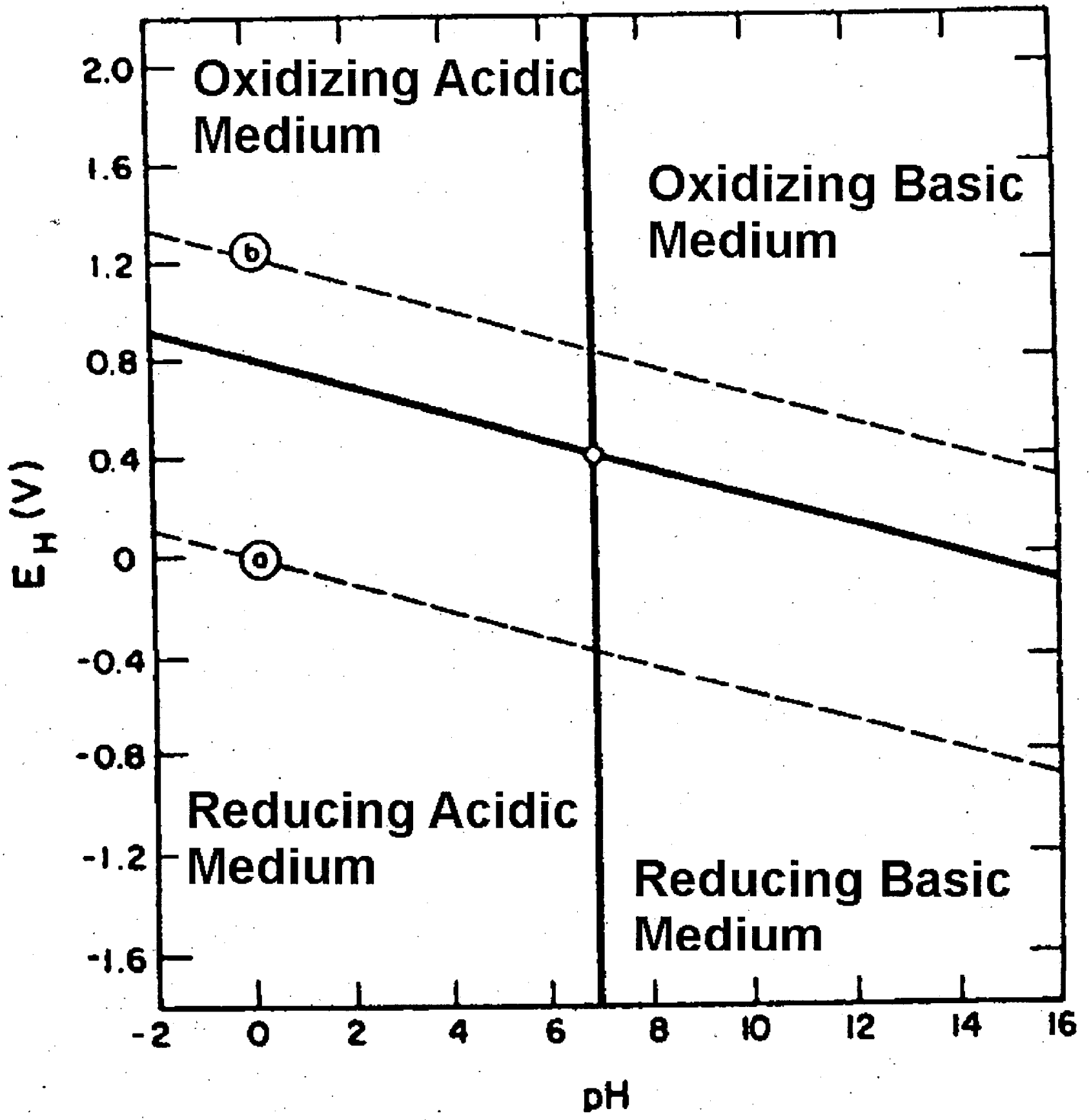

Figure 2 Acidic,alkaline and reducing media[2] 


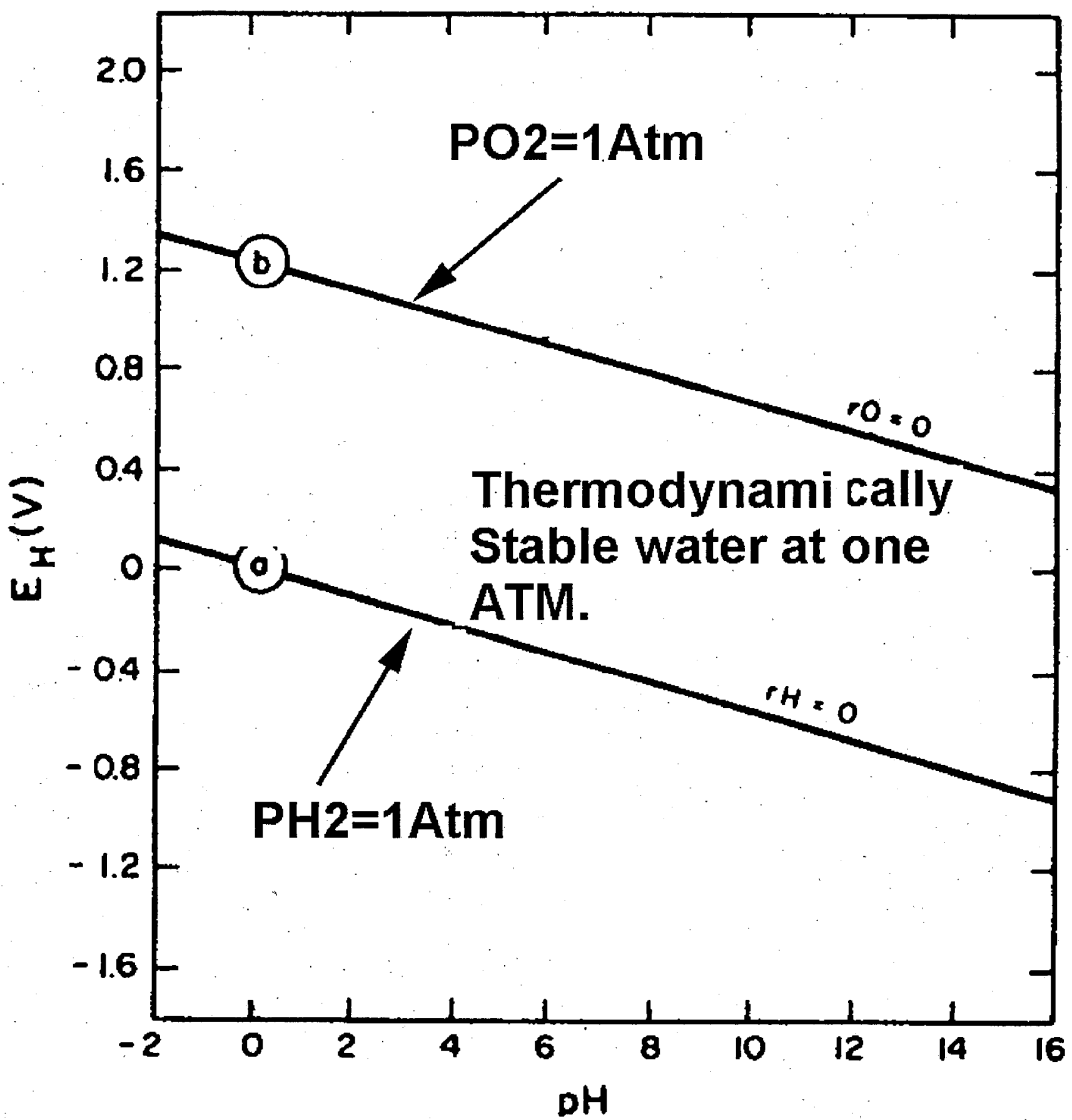

Figure 3.Region of thermodynamic stability of water at One Atmosphere and 25C[2]. 

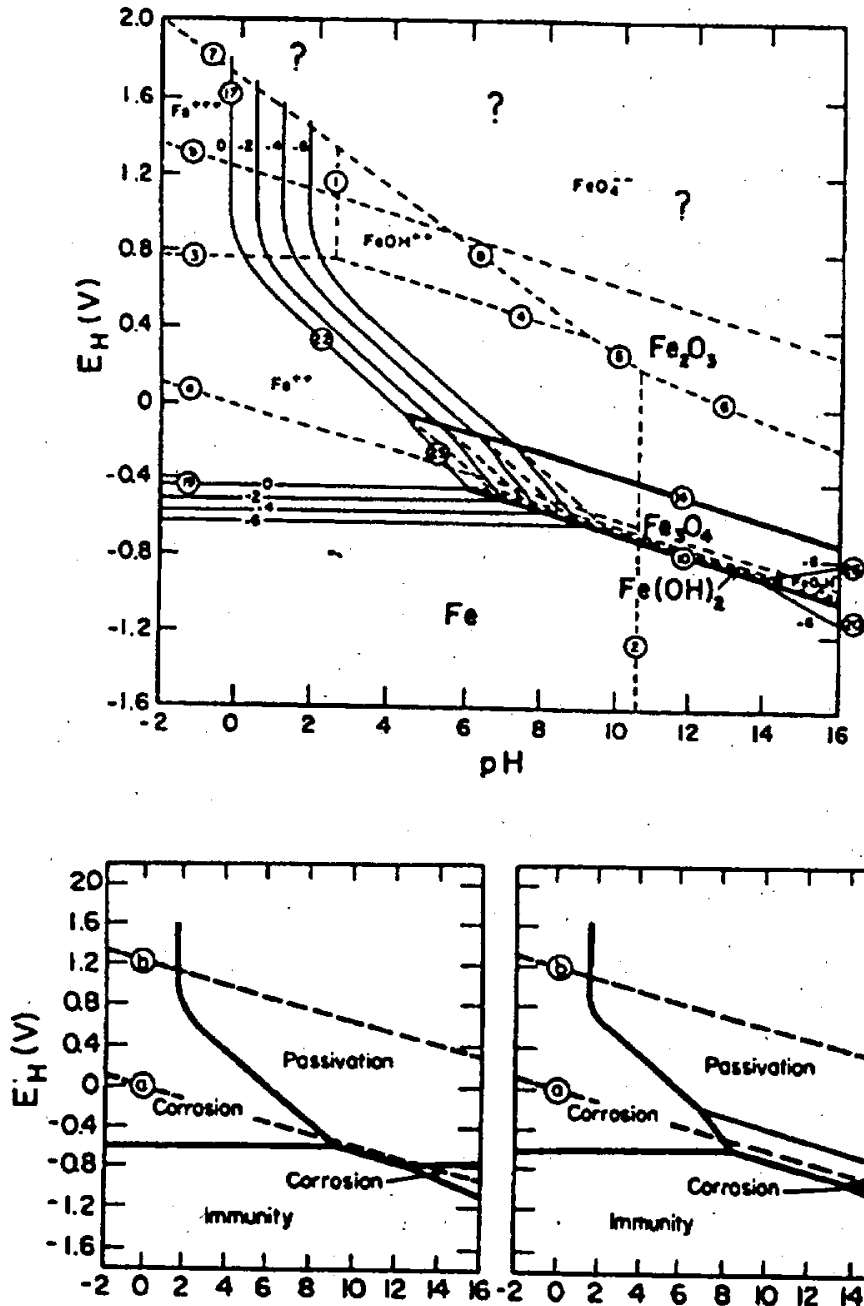

(o)

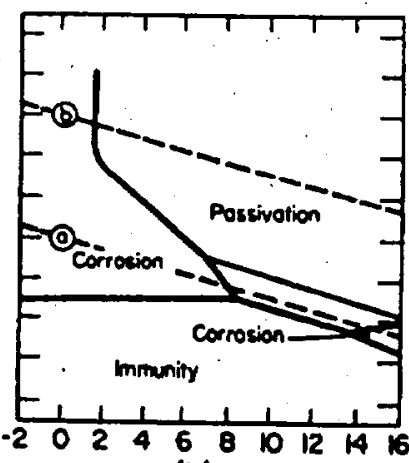

(b)

lution of oxygen; and the region between the two lines $a$ and $b$ represents the circumstances in which both this reduction and oxidation are impossible. Water then is thermodynamically stable and this region represents the region of thermodynamic stability of water under 1 atm pressure.

Depending on the actual conditions of $\mathrm{pH}$ and electrode potential, the oxidation of iron may give rise to soluble products -green ferrous ions, $\mathrm{Fe}^{++}$, yellow ferric ions, Fet+t, and green dibypoferrite ions, $\mathrm{FeO} \mathrm{H}^{-}-\mathrm{ot}$ to insoluble products-white lestous hydroxide $\mathrm{Fe}(\mathrm{OH})_{2}$ (unstable relative to black magnetite, $\mathrm{Fe}_{3} \mathrm{O}$ ) and brown ferric oxide, Fe, $\mathrm{O}_{3}$, which may be variously hydrated end is the main constituent of rust. For the sake of definition, iron is said to be corroding in the presence of an iron-free colution when the quantity of iron that this solution may dissolve is greater than a given low value (e.g., $10^{-\rightarrow} \mathrm{g}$-atoms/liter or 0.056 Ppm), and conversely iron may be rendered passive if it becomes covered by 2 protective insoluble oxide or hydroxide $\left(e .8\right.$., $\left.\mathrm{Fe}_{2} \mathrm{O}, \mathrm{s}\right)$. Then the lines which are drawn corresponding to a solubility of metal and its oxide equal to $10^{-1}$ delineate various regions or areas. There are two areas where corrosion is possible (areas of corrosion), an area where corrosion is impossible (arta of immunity's or cathodic protection),

pH

Figure 4.Theoretical Conditions of Corrosion, Imunity and Passivation of iron. The lower figures assume passivation by a film of $\mathrm{Fe}_{2} \mathrm{O}_{3}(\mathrm{a})$ and $\mathrm{Fe}_{2} \mathrm{O}_{3}$ and $\mathrm{Fe}_{3} \mathrm{O}_{4} \cdot[2]$ 


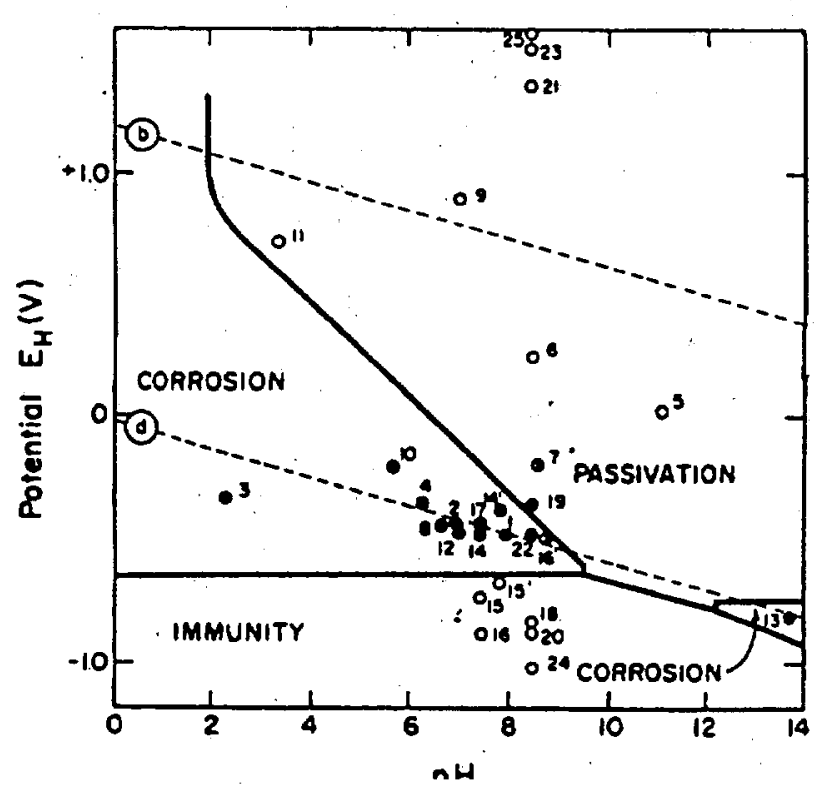

conditions or corrosion, immunity, and passivation. This assumes that the insoluble products, $\mathrm{Fe}_{2} \mathrm{O}_{2}$ and $\mathrm{Fe}_{2} \mathrm{O}_{4}$, are sufficiently adberent and impermeable that corrosion of the underiying metal is exsentially stifled and the metal is then "passive."

The existence of the various regions of corrosion, immunity, and pastivation as a fuaction of potential and pH suggests that some definite experimental correlation is possible. If the $\mathrm{pH}$ and potential of the experiments of Figure 1 are measured (see Table III) and a notation is made of geacral corrosion (O), local corrosion (D), or absence of corrosion (O), then these results ean be correlated with the theoretical predictions. This correlation is shown in Figure 8.14.18 This figure shows that the conditions under which there is effoctive corrosion or absence of corrosion are in good agreement with the theoretical predictions. Especially, this Ggure shows that an oxidizing action either protects iron, or conversely increases the corrosion, depending on whether the particular value of electrode potential of the metal falls within the area of passivation or not. Aleo the figure shows that the cor. rosion of iron in contact with a degassed solution of caustic soda is due to the existence of an "area of corrosion" in alkaline solutions free from oxidants; an area which becomes more important at higher temperatures and

Figure 5.Theoretical and experimental conditions of corrosion(filled circles) and non corrosion of iron (open circles) at $25 \mathrm{C}$ and one atmosphere.[2] 


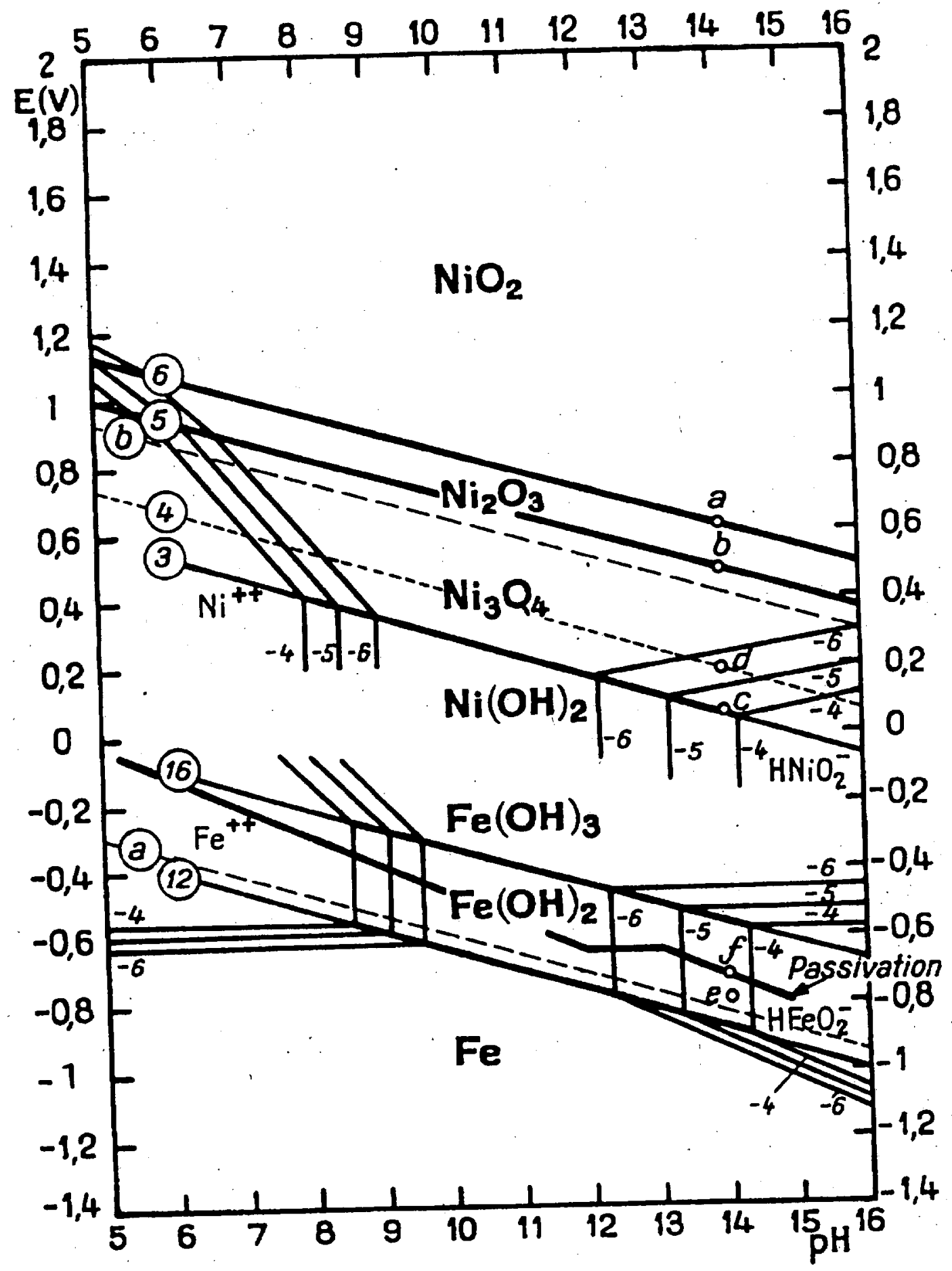

Fig. 6. Iron-nickel accumulators.

Figure 6. Pourbaix Diagrams for iron and nickel[2] 
The forgoing discussion of Pourbaix's work resulted from classical "hand calculations" of competing calculations of reactions which were farsighted for their time but limited in scope simply because of the necessary limitations on the number of different species and compounds that could be considered simultaneously.Moreover the thermodynamic data available to Pourbaix provided an additional limitation to his calculations.Figures 7-10 show the recent results of Thompson et.al[3] who calculated Pourbaix diagrams for multicomponent alloys using CT techniques. These figures show the results for pure iron and nickel in water at $25 \mathrm{C}$. The set of parallel lines in these diagrams refer to a variation of the concentration of $\mathrm{Fe}$ (or $\mathrm{Ni}$ ) of $1,10^{-2}, 10^{-4}$, and $10^{-6}$ respectively.These diagrams support the original findings of Pourbaix using modern computational methods and experimental data.The main point of the the recent work[3] is to demonstrate that a full application of Pourbaix's methods to multicomponent alloys cannot ignore the formation of mixed oxide phases(in this case $\mathrm{NiFe}_{2} \mathrm{O}_{4}$ ) that are stable and can substantially alter the topography of the diagram and the corrosion resistance of iron-nickel alloys!Thus Fig. 9 and 10 show the effect of including this phase in the calculations as well as the substantial changes that are predicted for the nature of the phases that exist at various points in Eh-pH space!

As indicated earlier the Thermo-Calc software and the extensive Thermo-Calc Databases have been applied with great success in defining and predicting critical chacacteristics of phase stability and transformations in C-22[1].Recently a Pourbaix module has bee installed and integrated into the ThermoCalc software package.Successful utilization of this TCAQ software in concert with the extensive SSOL and SUB94 databases in defining the behavior of C-22 in the Variety of J-13 Wellwaters noted above would provide substantial insight into the corrosion behavior of this critical Waste Package alloy:During the initial pahse of the current study substantial progress has been made in demonstrating the feasibility of successfully attaining this goal.The results todate are provided below in Figures 11-17.

\section{Application of Thermo-Calc Software to Calculation of the Pourbaix Diagrams of C-22 in J-13 Wellwaters}

Figure 11 shows the Pourbaix diagram for Ni calculated using the TCAQ module in Thermo-Calc.It compares favorably with those presented in Figure 6[2] and Figure 8[3].In order to gain some insight into the expected diagrams for $\mathrm{C}-22$ which contains major quantities of $\mathrm{Ni}, \mathrm{Cr}, \mathrm{Mo}, \mathrm{Co}, \mathrm{W}$, and $\mathrm{Fe}$ as well as $\mathrm{C}, \mathrm{Si}, \mathrm{Mn}$ and V[1] it is instructive to consider Figures 12 and 13 from Pourbaix [2] for $\mathrm{Cr}$ and Mo which are present at levels of 22 and 13 weight percent respectively. These figures show that the addition of $\mathrm{Cr}$ and Mo substantially expand the range of solid phases like $\mathrm{Cr}_{2} \mathrm{O}_{3}, \mathrm{MoO}_{2}$, and $\mathrm{MoO}_{3}$,on the diagram. This is true even in the absence of the spinells they form with the other components of $\mathrm{C}-22$.For example, $\mathrm{NiCr}_{2} \mathrm{O}_{4}$ and $\mathrm{NiFe}_{2} \mathrm{O}_{4}$ ! Consequently it is to be expected that the Pourbaix diagram for C-22 will exhibit a substantial expansion of the regions where solid phases exist in Figure 11 due to the addition of $\mathrm{Cr}$ and Mo.Moreover additions of $\mathrm{Fe}$ and $\mathrm{W}$ are expected to increase the ranges of solid phases even more. This is a clear explanation of the corrosion resistance of $\mathrm{C}-22$ and why it was chosen as the leading candidate for the waste package!Figure 14 shows the calculated Pourbaix diagram for a siulated $\mathrm{C}-22$ containing Ni with $22 \mathrm{w} / \mathrm{o} \mathrm{Cr}$ and $13 \mathrm{w} / \mathrm{o}$ Mo and ignoring the remaining alloying elements. The concentration of $1 \mathrm{gm}$ of metal in $1000 \mathrm{gm}$ of water is about $.05 \mathrm{~m}$. The major solid phases that appear are those expected from the forgoing diagrams shown in Figs6-8,12 and 13[2,3]. The only addition is the spinell phase which has been added provisionally on the bases of experimental observations [4].This spinell is a $\mathrm{Ni}(\mathrm{Cr}, \mathrm{Mo})_{2} \mathrm{O}_{4}$ phase which is designated by SP in Figure 14.It is likely that the addition of $\mathrm{W}$ and $\mathrm{Fe}$ will further extend the field of this SP phase on the Pourbaix diagram. This should be investigated experimentally! 


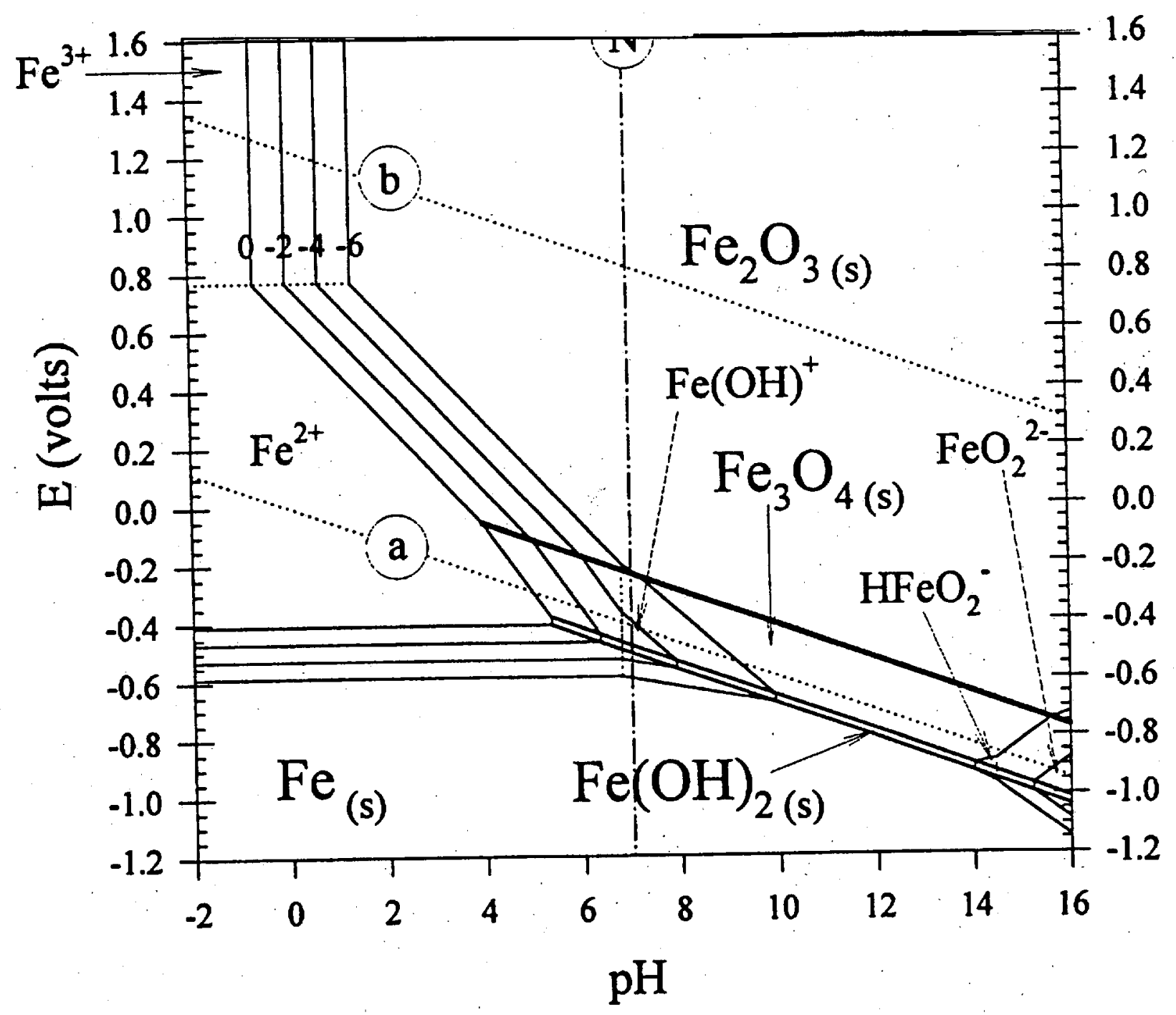

Figure 7 The Fe Pourbaix diagram at $25 \mathrm{C}$ aqueous species range from 1 to $10^{-6} \mathrm{~m} .[3]$ 


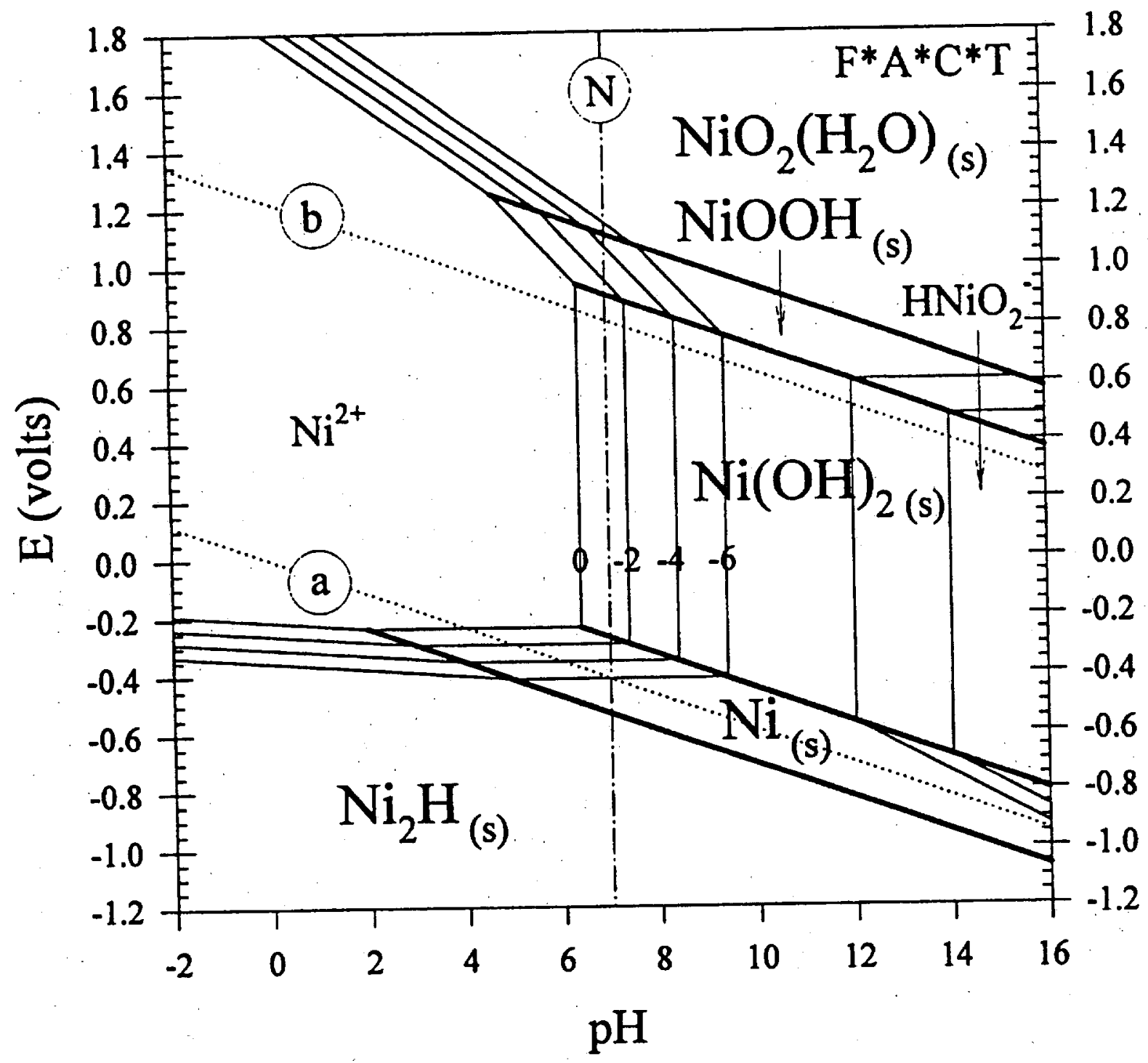

Figure 8.The Pourbaix diagram at $25 \mathrm{C}$ for Ni.Concentrations of aqueous species range from 1 to $10^{-6} \mathrm{~m}$.[3] 


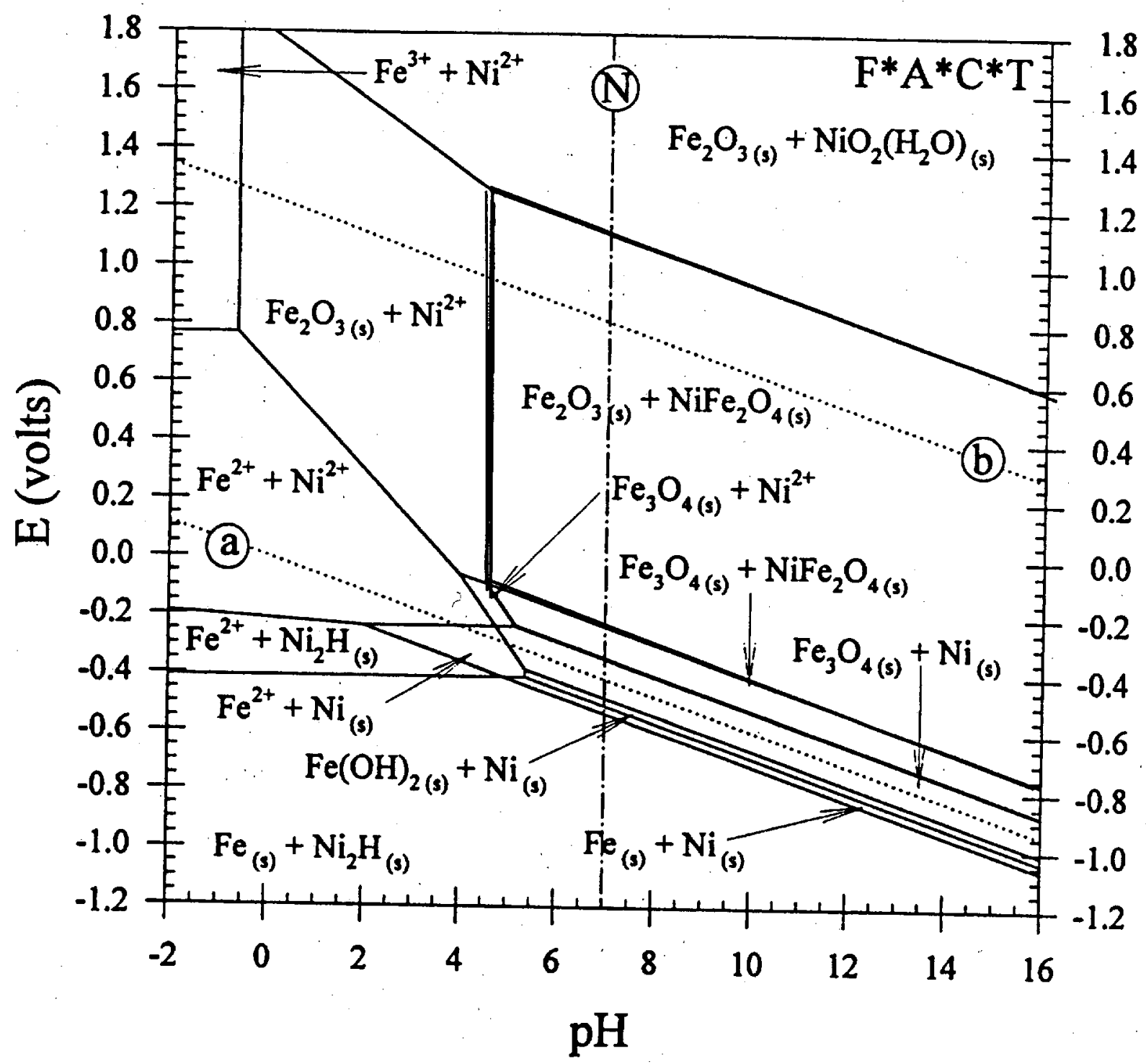

Figure. 9 The Fe-Ni composite Pourbaix diagram at 25C.The concertrations of all aqueous species is $1 \mathrm{~m}$. The molar proportion of $\mathrm{Fe}$ to $\mathrm{Ni}$ is $>2: 1$. The specific proportion affects the phase proportions in each doubly labled field but does not affect the topology until the ratio falls below below 2:1(when,e.g., $\mathrm{NiFe}_{2} \mathrm{O}_{4}$ could not coexist with $\mathrm{Fe}_{2} \mathrm{O}_{3}$ for mass balance reasons). Note placement of $\mathrm{NiFe}_{2} \mathrm{O}_{4}$ solid spinel, which is outlined in bold[3] 


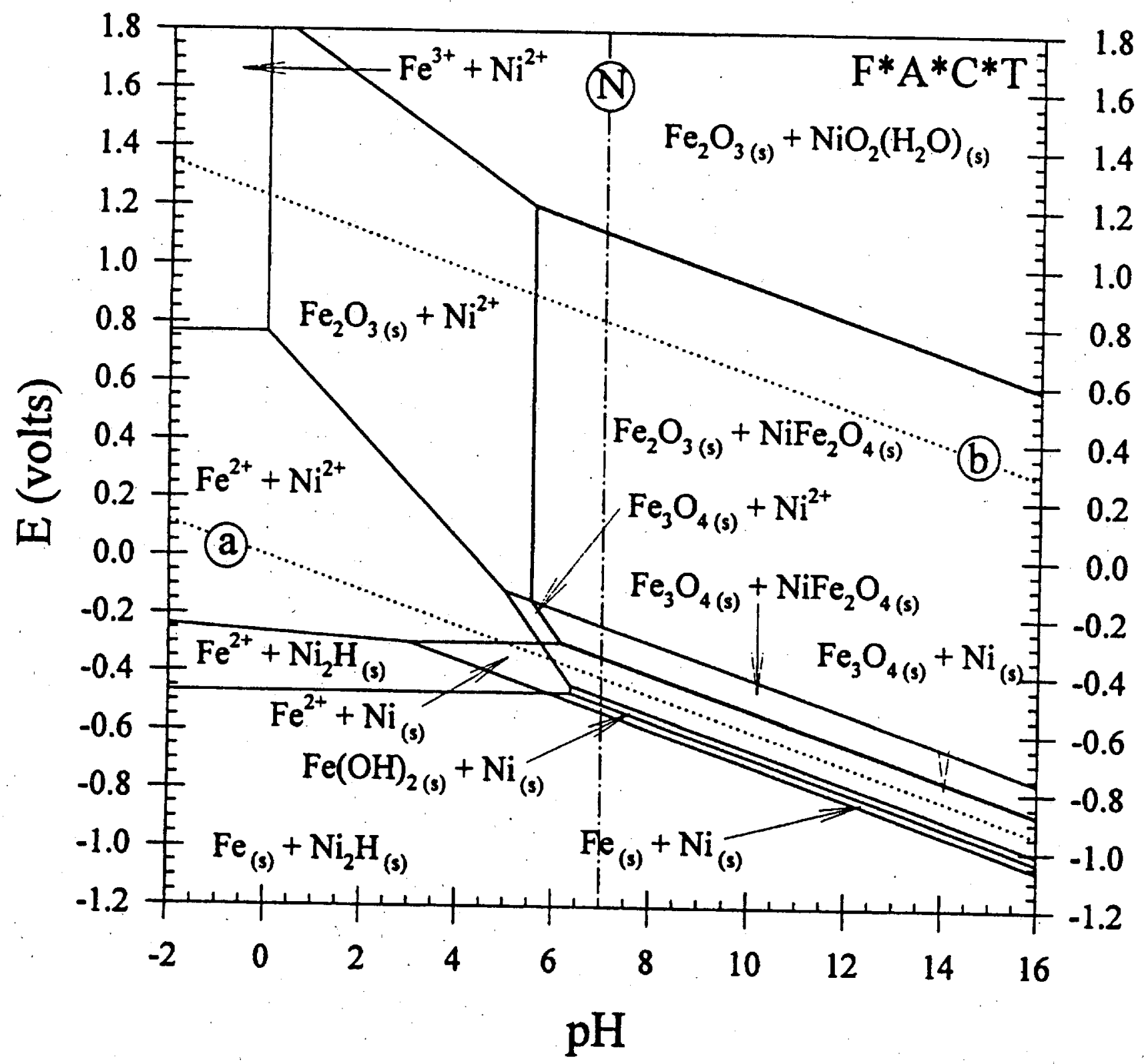

Figure.10 The Fe-Ni composite Pourbaix diagram at 25C.The concertrations of all aqueous species is $01 \mathrm{~m}$. The molar proportion of $\mathrm{Fe}$ to $\mathrm{Ni}$ is $>2: 1$ Note placement of $\mathrm{NiFe}_{2} \mathrm{O}_{4}$ solid spinel, which is outlined in bold[3]. 


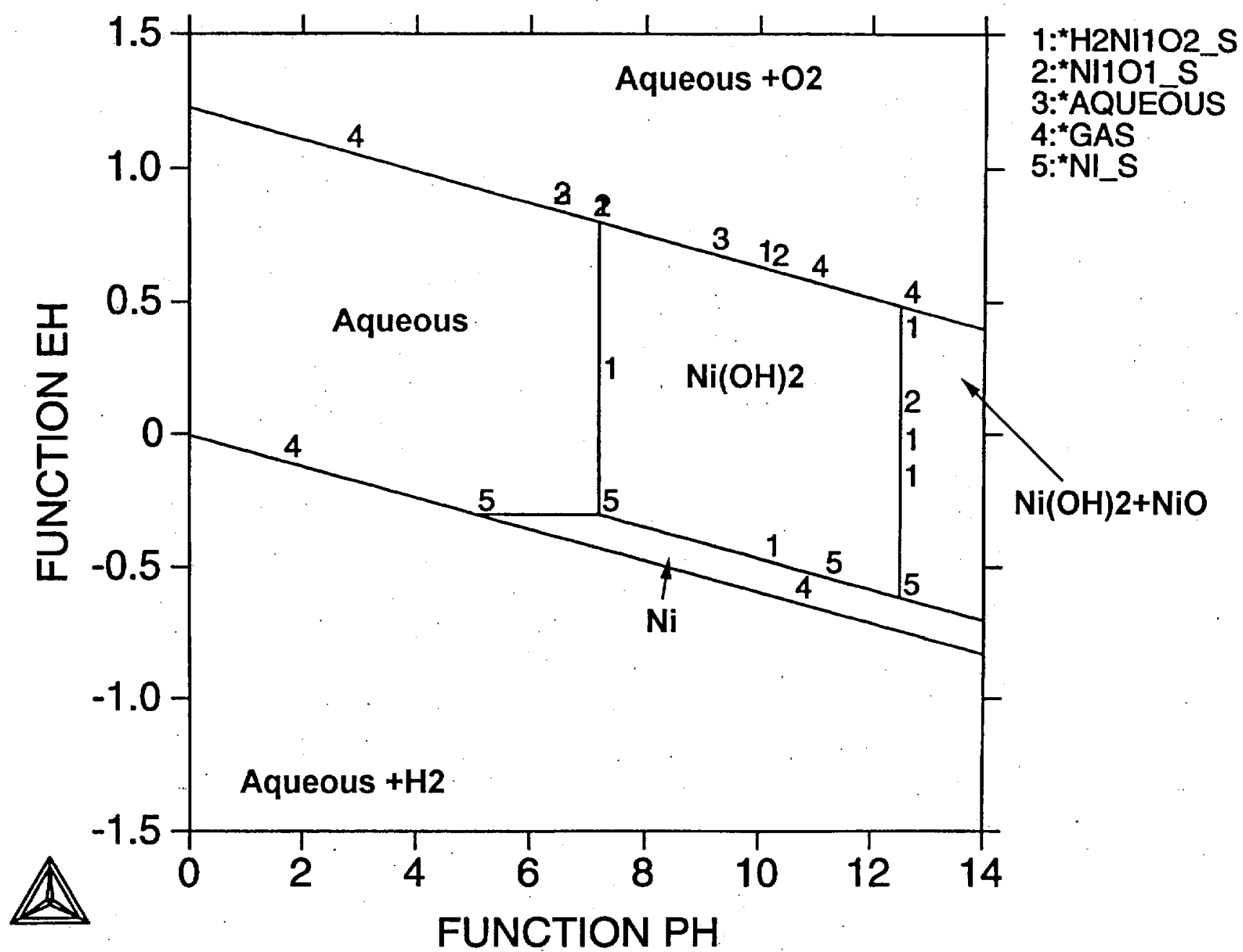

Figure 11. Calculated Pourbaix diagram for one gram of $\mathrm{Ni}$ in 1000 grams of water at $25 \mathrm{C}$. 


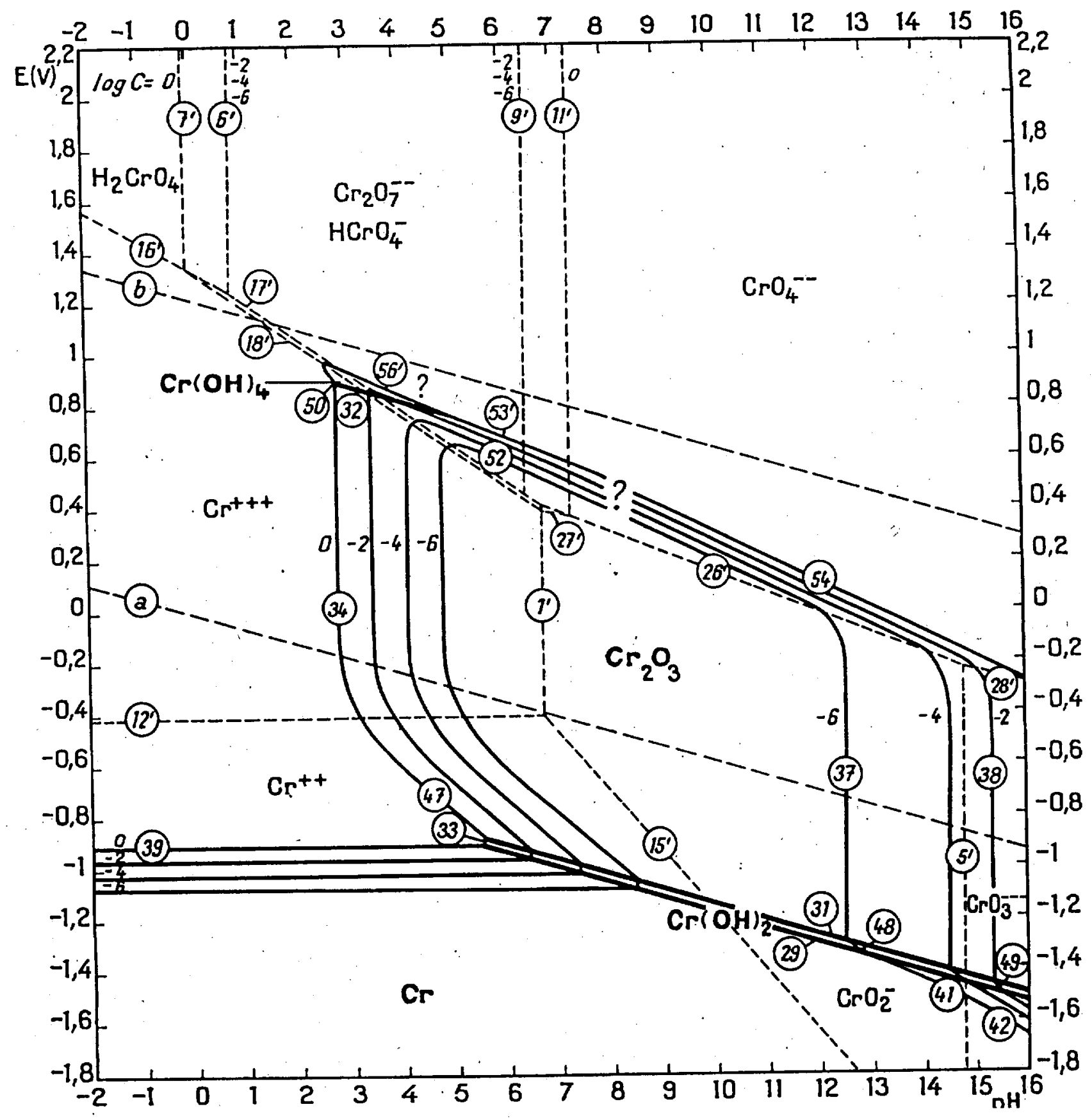

Figure 12.Potential-pH equilibrium diagram for the system chromium water at 25C [2] 


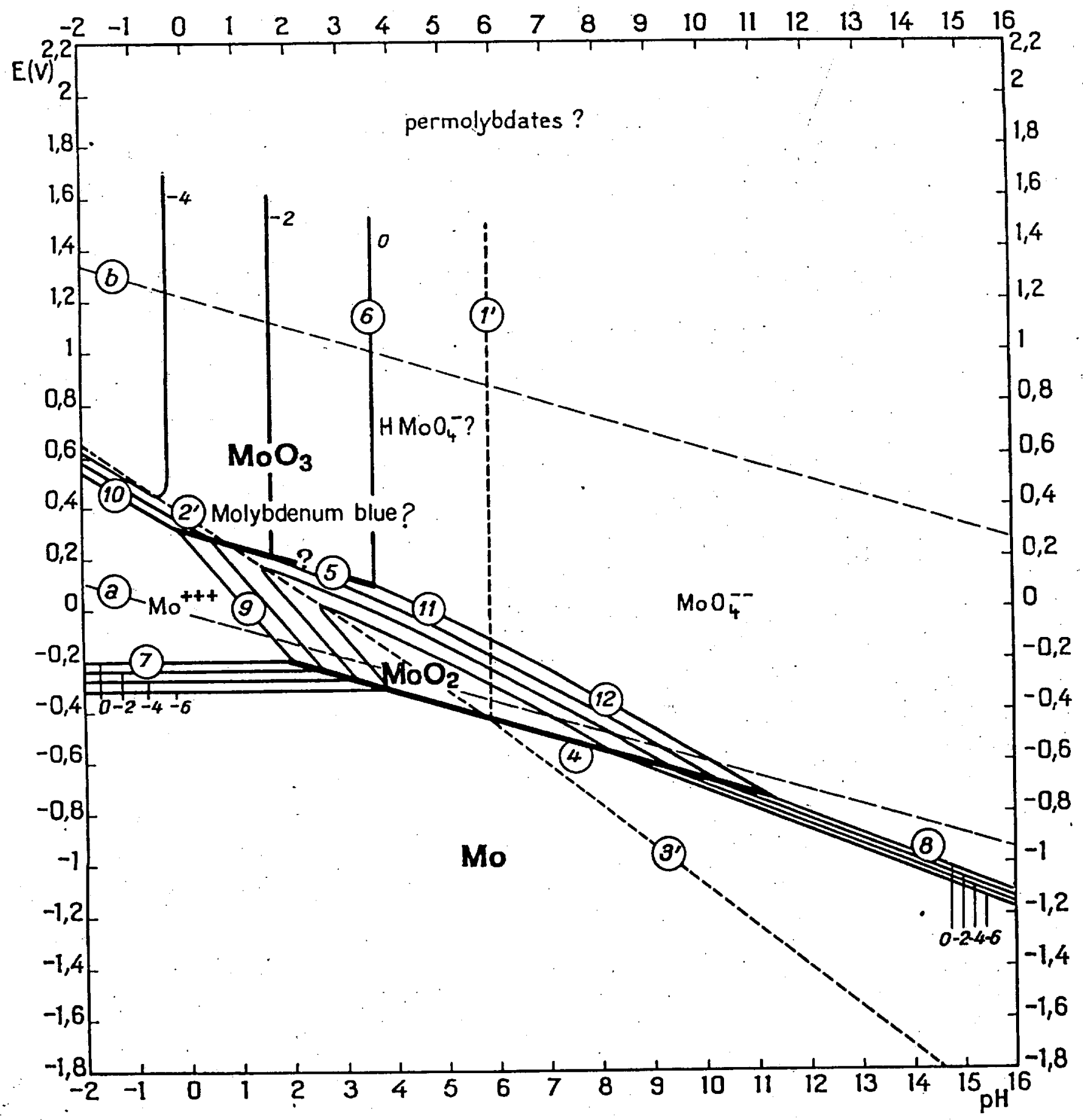

Figure 13. Potential-pH equilibrium diagram for the system for molybdenum at $25 \mathrm{C}[2]$. 


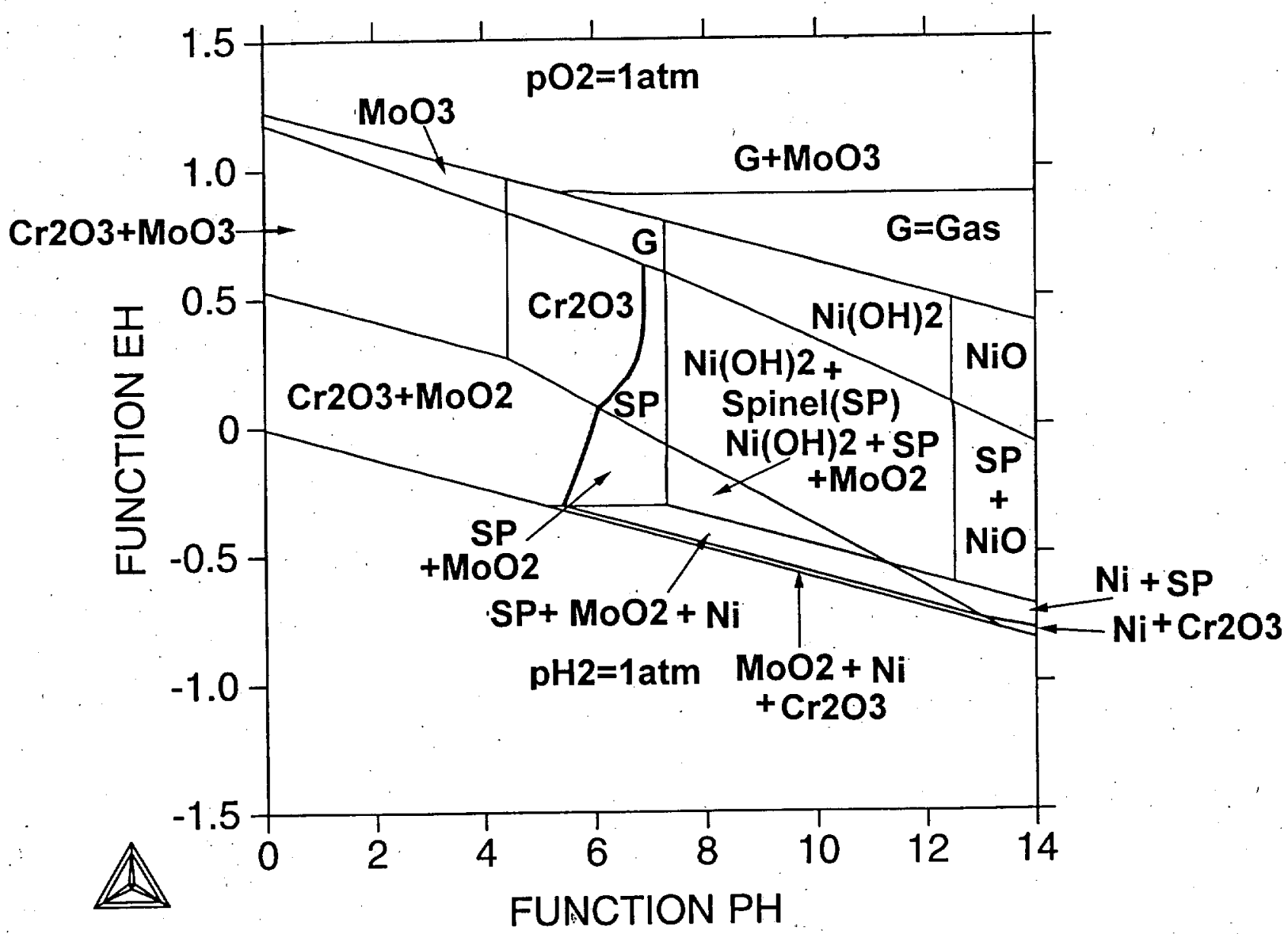

Figure 14.Pourbaix Diagram for .65Ni-.22Cr-.13Mo(total $1 \mathrm{gm}$.) in $1000 \mathrm{~g}$ of water at $25 \mathrm{C}$ and one atmosphere. The entire diagram is covered by an Aqueous Solution(Pure water in this case) 


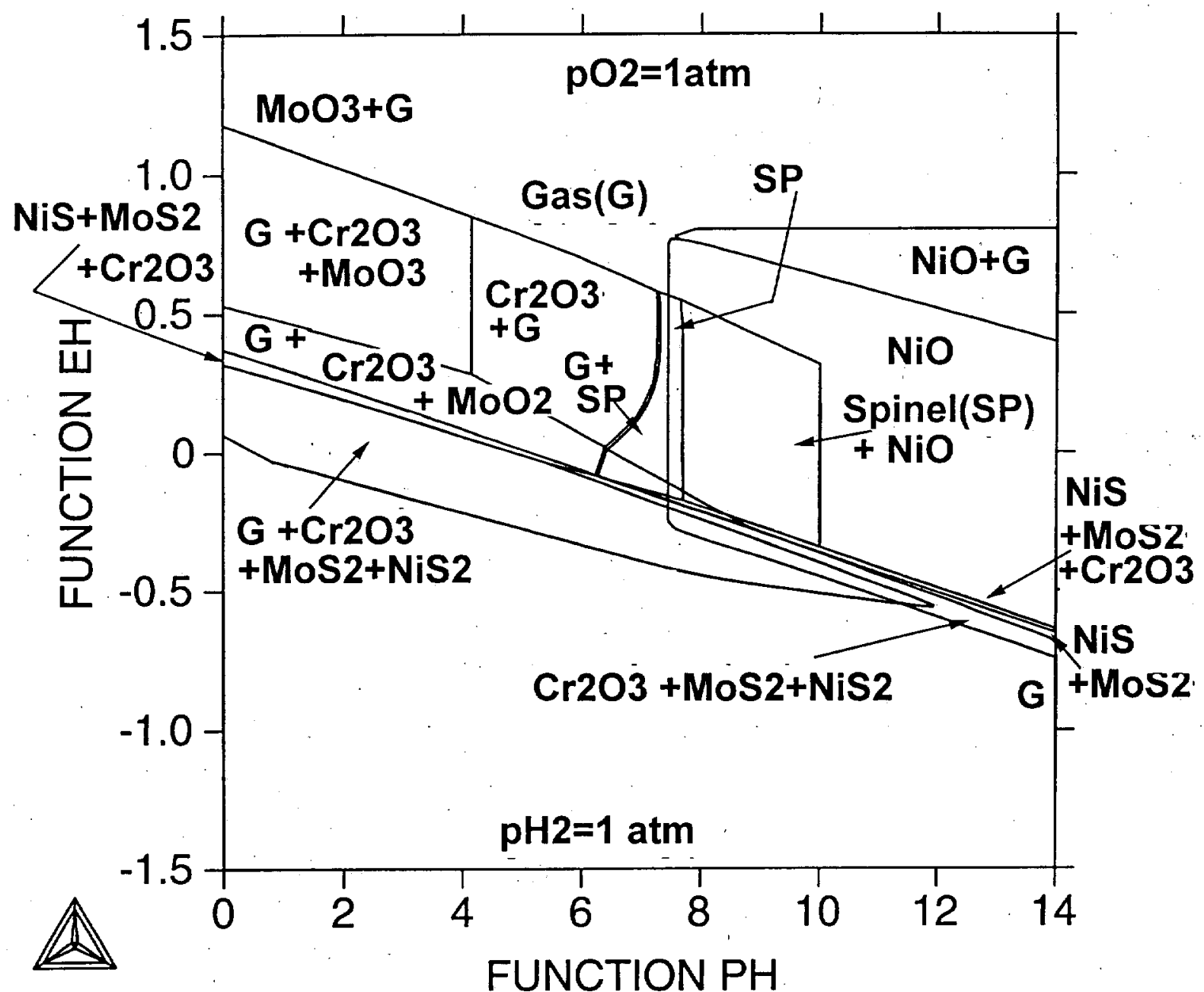

Figure 15.Pourbaix Diagram for $.65 \mathrm{Ni}-.22 \mathrm{Cr}-.13 \mathrm{Mo}($ total $1 \mathrm{gm}$.) in $1000 \mathrm{~g}$ of water at $25 \mathrm{C}$ and one atmosphere. The water contains $40.9 \mathrm{~g}(\mathrm{Na}+1), 70 \mathrm{~g}(\mathrm{HCO} 3-1), 16.4 \mathrm{~g}(\mathrm{SO} 4-2)$ and $6.7 \mathrm{~g}(\mathrm{Cl}-1)$. The entire diagram is covered by the Aqueous SCW solution. The 6.4g(NO3-1),3.4g(F-1), $0.0005 \mathrm{~g}(\mathrm{Ca}+2)$ and $0.0005(\mathrm{Mg}+2)$ have been omitted. 


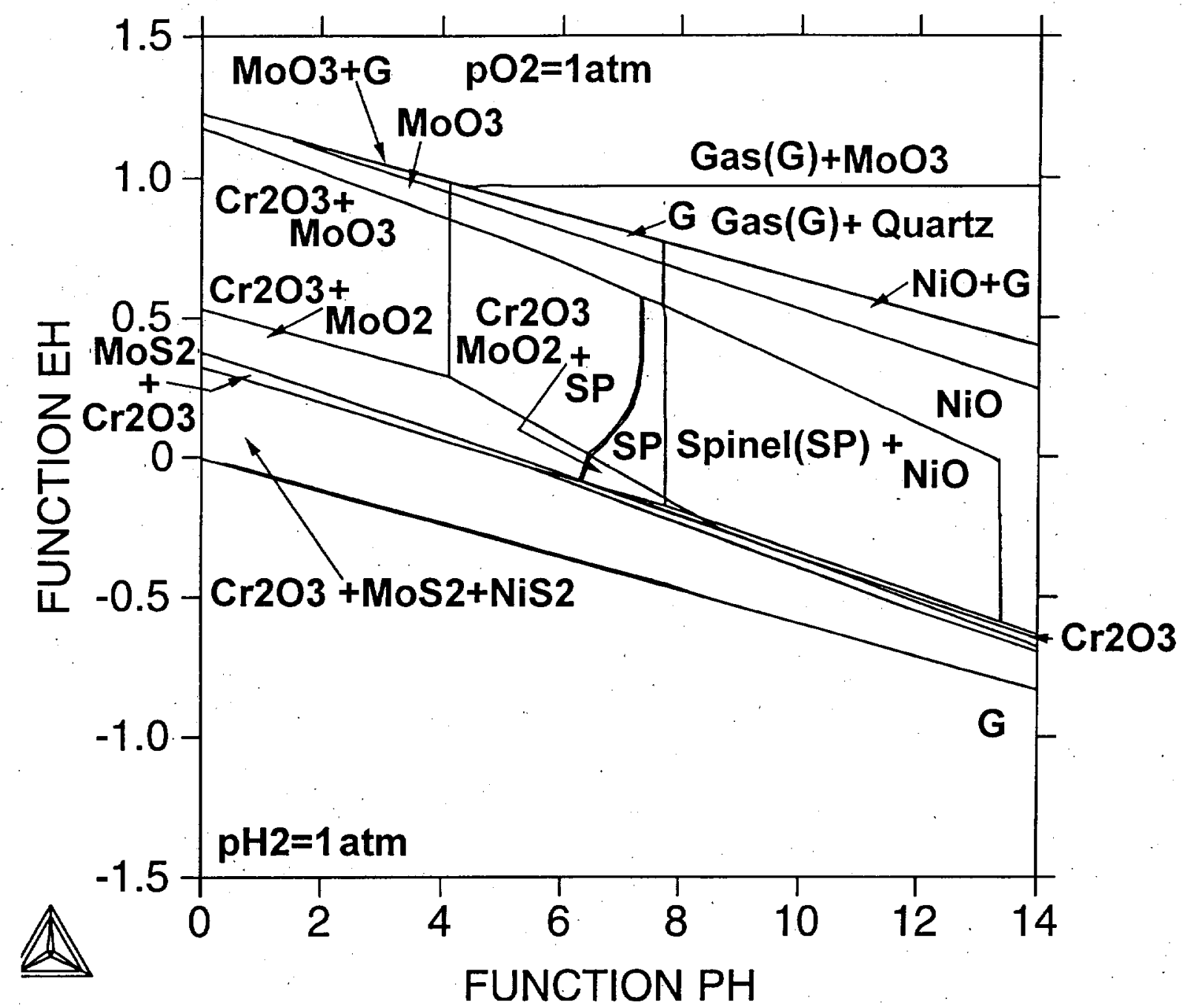

Figure 16.Pourbaix Diagram for $.65 \mathrm{Ni}-.22 \mathrm{Cr}-13 \mathrm{Mo}($ total $1 \mathrm{gm}$.) in $1000 \mathrm{~g}$ of water at $25 \mathrm{C}$ and one atmosphere. The water contains $38.86 \mathrm{~g}(\mathrm{Na}+1), 38.6 \mathrm{~g}(\mathrm{SO} 4-2)$ and $24.25 \mathrm{~g}(\mathrm{Cl}-1)$ 23.0(NO3-1),3.4g(K+1) and $0.13 \mathrm{~g}(\mathrm{H} 2 \mathrm{SiO} 3)$. The entire diagram is covered by the Aqueous SAW solution. 


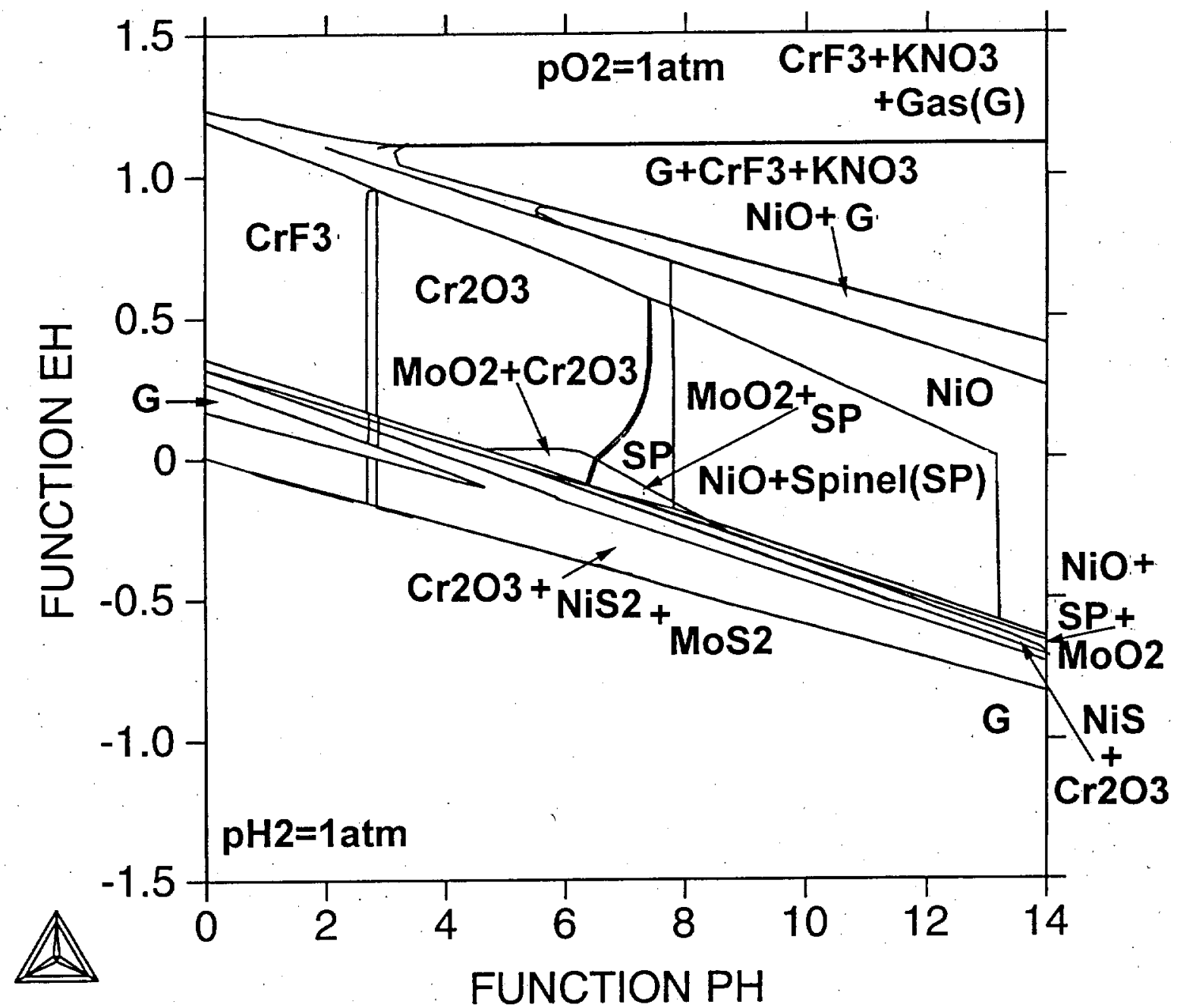

Figure 17.Pourbaix Diagram for .65Ni-.22Cr-.13Mo(total $1 \mathrm{gm}$.) in $1000 \mathrm{~g}$ of water at $25 \mathrm{C}$ and one atmosphere. The water contains $105.8 \mathrm{~g}(\mathrm{Na}+1), 14.7 \mathrm{~g}(\mathrm{SO} 4-2)$ and $130.83 \mathrm{~g}(\mathrm{Cl}-1)$ $132.65 \mathrm{~g}(\mathrm{NO} 3-1), 67.62 \mathrm{~g}(\mathrm{~K}+1)$ and $1.47 \mathrm{~g}(\mathrm{~F}-1)$. The entire diagram is covered by th1s Aqueous BSW solution. 


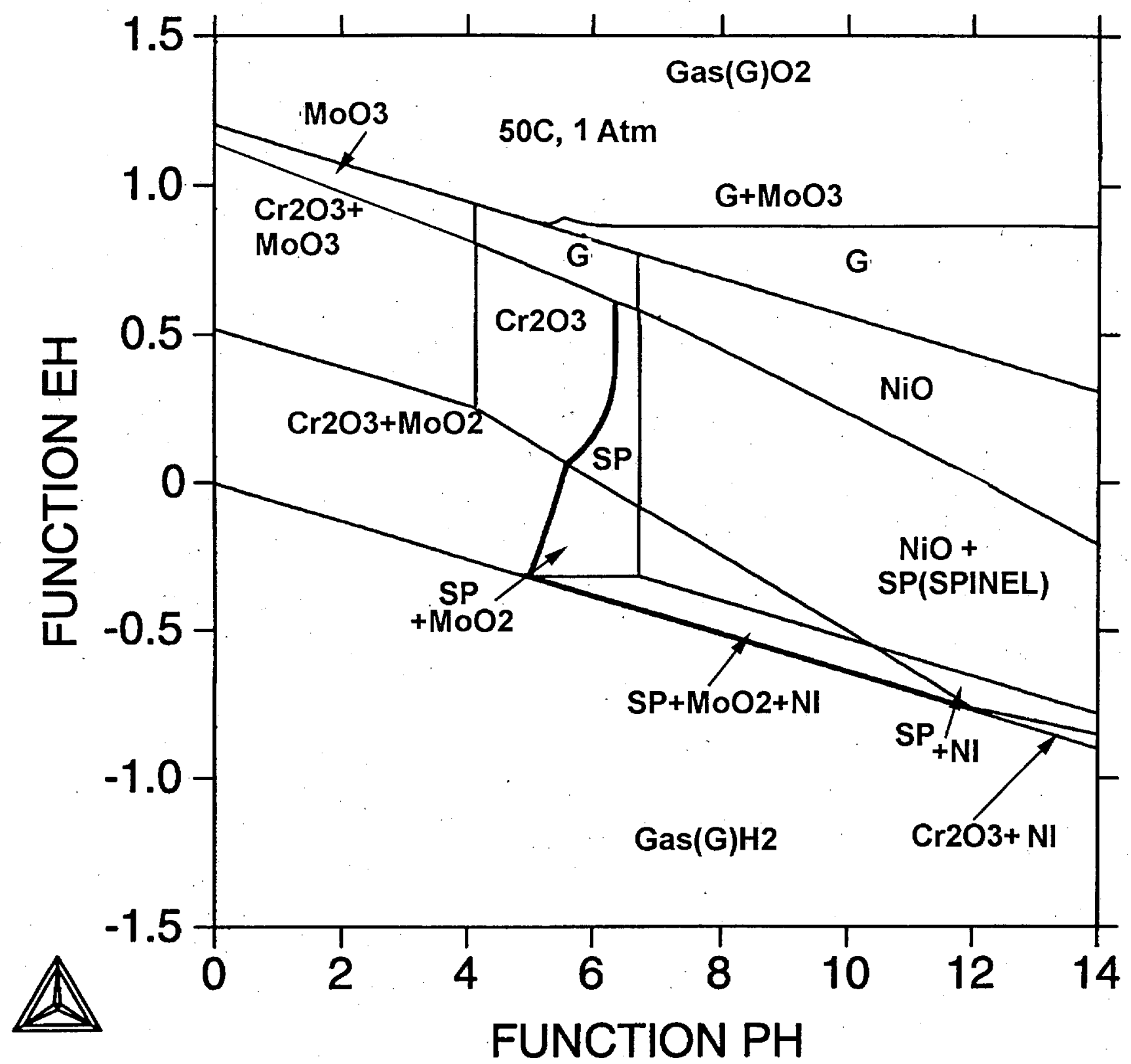

Figure 18. Calculated Pourbaix Diagram for $.65 \mathrm{Ni}-.22 \mathrm{Cr}-.13 \mathrm{Mo}($ total $1 \mathrm{gm}$.) in $1000 \mathrm{gms}$. of water at $50 \mathrm{C}$ and 1 atmosphere.

The most difficult part of the study to date was generation of the Pourbaix diagrams for C-22 in the three Simulated J-13 Wellwaters including SAW,BSW and SCW!As indicated in Figures15-17 small quanties of $\mathrm{Ca}+2$ and $\mathrm{Mg}+2$ along with NO3-1 and F-1 have been omitted in the SCW calculation(Fig15) In addition $1 \mathrm{gm}$ 


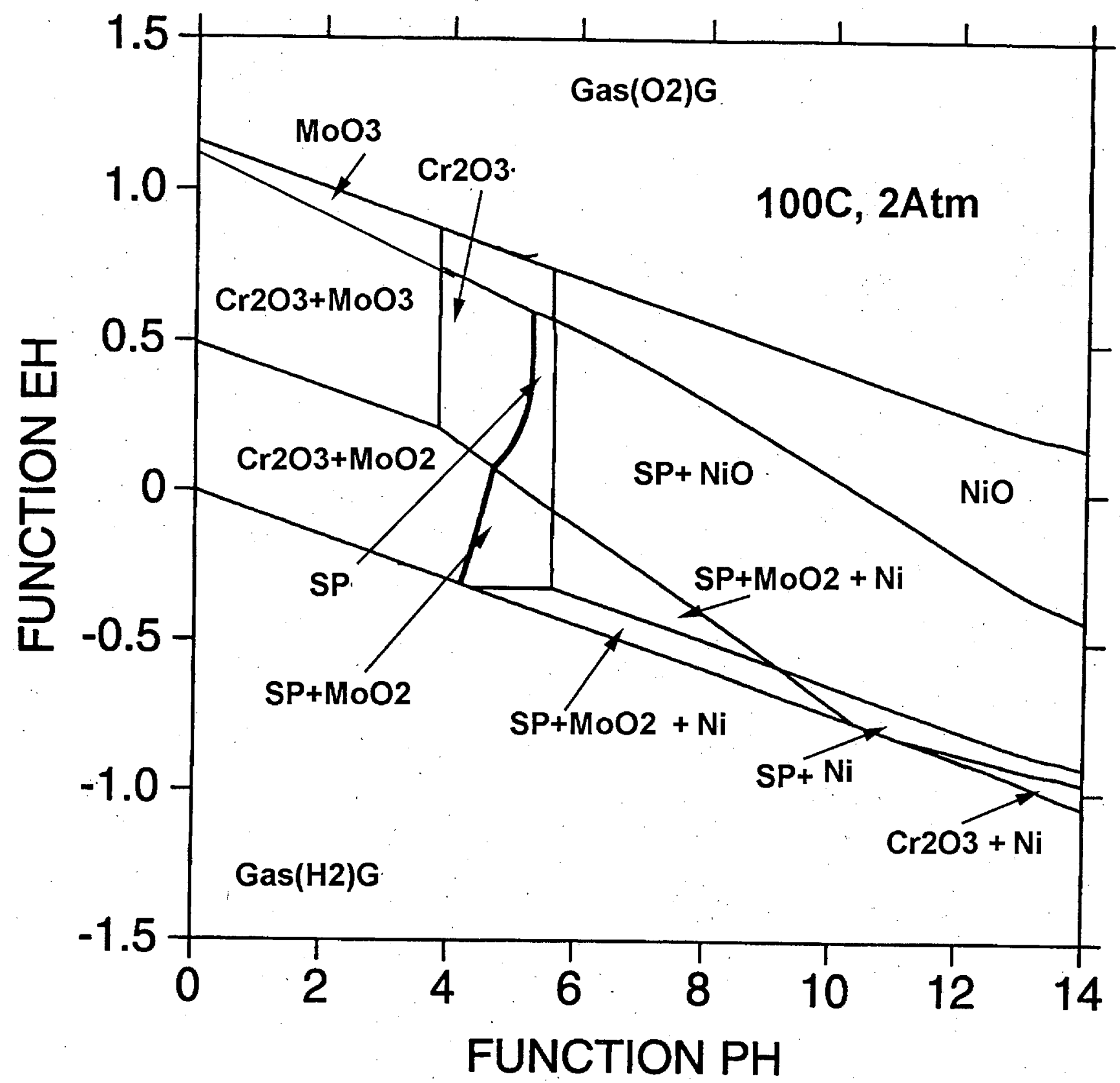

Figure 19.Calculated Pourbaix Diagram for .65 Ni-.22Cr-.13Mo(1 gm.total) in 1000 gms. of water at $100 \mathrm{C}$ and 2 Atmospheres.

of $\mathrm{Ca}+2$ was omitted in the SAW calculation. The complete BSW solution was run as shown in Figure 17.The cause of the difficulties in performing the calculations for the J-13 solutions is that when all of the components are added they generate more than 300 species which must be considered during the individual runs as the computer program explores the Eh-pH space.this increases the chance of errors due to non-convergence and program shutdown.Efforts will be made to selectively reduce the number of species to eliminate this problem. Currently any species which is present at a concentration level exceeding $10^{-30}$ is included in the calculation. This limit may be increased to eliminate some of the species. 


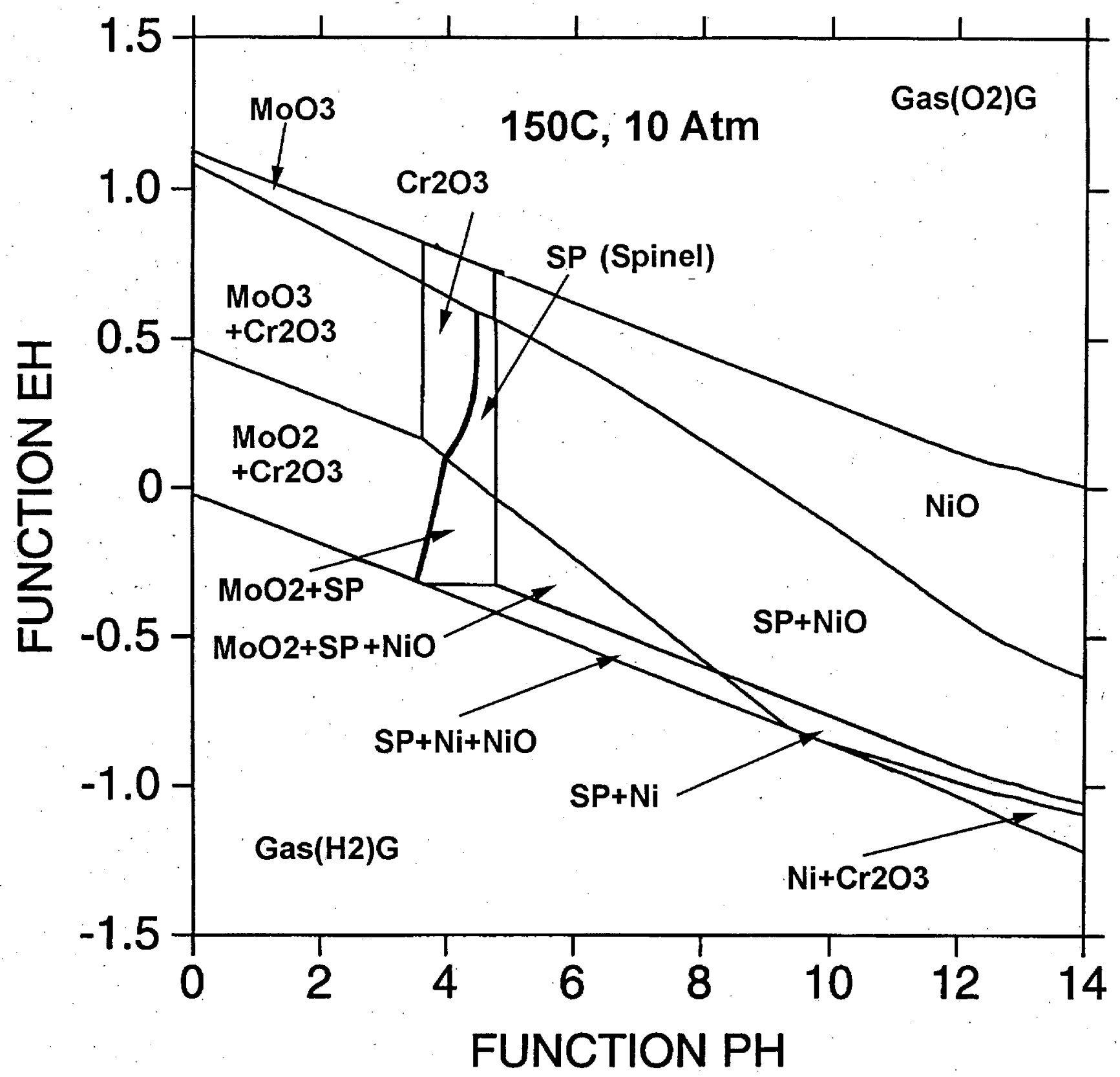

Figure 20.Calcualated Pourbaix Diagram for .65Ni-.22Cr-.13Mo in $1000 \mathrm{gms}$ of water at $150 \mathrm{C}$ and 10 Atm. pressure.

In spite of these problems Figures 15-17 present many interesting features that offer practical insight into the expected behavior of $\mathrm{C}-22$ in the various Wellwaters. The first is the nature of the solids that are exceted to form and the Eh values at which they form in different environ ments. The second is the regions where the gas phase appears in the different Wellwaters.Figures 18-21 show the Pourbaix diagrams for .65Ni-.22Cr-.13Mo(1 gm total) in $1000 \mathrm{gms}$. of water at $50 \mathrm{C}, 100 \mathrm{C}, 150 \mathrm{C}$ and $200 \mathrm{C}$.In these cases the pressure was raised above one atmosphere to suppress the formation of gaseous phases. The boiling points for pure water at these temperatures are $.03, .11,1,4.5$, and $15 \mathrm{~atm}$. respectively. 


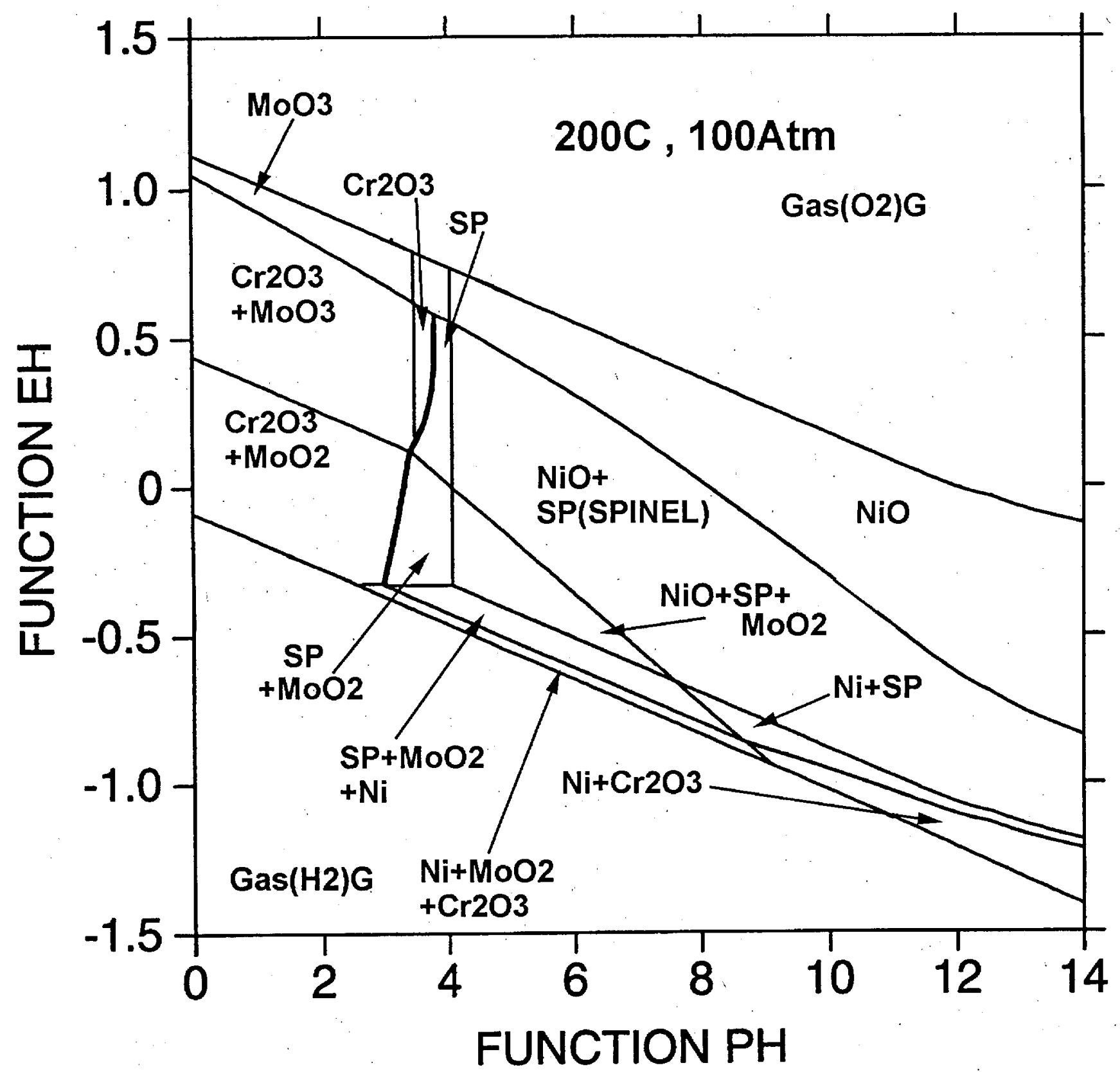

Figure 21. Calculated Pourbaix diagram for $.65 \mathrm{Ni}-.13 \mathrm{Cr}-.22 \mathrm{Mo}(1 \mathrm{gm}$ total) in $1000 \mathrm{gms}$. of water at $200 \mathrm{C}$ and $100 \mathrm{Atm}$. 
The next phase of the study will include raising the temperature up to $200 \mathrm{C}$ in the well waters and adding $\mathrm{W}$ and $\mathrm{Fe}$ to approach the $\mathrm{C}-22$ composition more closely.

\section{References}

\section{L.Kaufman,CALPHAD,25(2001)141}

2.Marcell Pourbaix, "Lectures on Electrochemical Corrosion" Translated by J.A.S.Green,Edited by Roger Stahle,Plenum Press New Yorl,London(1973),ISBN 0-306-30449-X

3.W.T.Thompson,M.H.Kaye,C.W.Bale and A.D.Pelton,"PourbaixDiagrams for Multielement Systems"

Uhlig's Corrosion Handbook,Second edition,Edited by R.Winston Revie,2000 John Wiley and Sons. ISBN:0-471-15777-5

4.R.D.McCright,LLNL,Private Communication,2001

This work was performed under the auspices of the U.S. Department of Energy by the University of California, Lawrence Livermore National Laboratory under Contract No. W-7405-Eng-48. 